\title{
Anionic Polymerization of Methyl Methacrylate in Tetrahydrofuran
}

\author{
Itaru Mita, Yoji Watabe, Takahiro Akatsu, \\ and Hirotaro KAMBE \\ Institute of Space and Aeronautical Sciences, University of \\ Tokyo, 6-1, Komaba-4, Meguro-ku, Tokyo, Japan
}

(Received April 21, 1972)

\begin{abstract}
Anionic polymerization of MMA in THF was studied by a capillary flow method with the dianion of $\alpha$-methylstyrene tetramer and sodium naphthalene as initiators. From the analysis of the methanol formed, it was found that both the initiation and propagation reactions proceed without side reaction at $-78^{\circ} \mathrm{C}$. However, at $c a .-65^{\circ} \mathrm{C}$, a certain amount of initiator is consumed by carbonyl attack in the initiation step though no side reaction is observed in the propagation step. At room temperature, the carbonyl attack is found in both steps and the polymerization stops at a certain degree of polymerization. The apparent propagation rate constants were determined at $-78^{\circ} \mathrm{C}$ and $c a .-65^{\circ} \mathrm{C}$. They increase with rising temperature and become too high to be determined at room temperature. The dependence of the rate constants on the propagating anion concentration revealed that the contribution of free ion to the propagation is relatively small and that the propagation rate constant of ion pair is about $1 \times 10^{2} l \mathrm{~mol}^{-1} \mathrm{sec}^{-1}$ at these low temperatures. These data are compared with the rates of homopolymerization of styrene and the reactivities of the propagating species of the two monomers are discussed.
\end{abstract}

KEY WORDS Anionic Polymerization / Polar Solvent / Methyl

Methacrylate / Initiation / Propagation / Rate Constant / Ion Pair /

Carbonyl Attack

Anionic polymerization of MMA is strongly affected by both solvents and gegen ions. Hitherto, most of its kinetic studies have been made in nonpolar solvents with $\mathrm{Li}^{+}$as a gegen ion. ${ }^{1-6}$ The mechanism of anionic polymerization of MMA in these systems is very complex and the molecular weight distribution of the polymer obtained is usually very broad..$^{2-4}$. One of the main reasons for this peculiar behavior of the polymerization is the strong coordination of $\mathrm{Li}^{+}$ with the carbomethoxy group. This coordination seems to be related to the formation of isotactic PMMA in nonpolar solvents. The peculiarity of the polymerization is partially retained in a mixed solvent such as toluene-THF when gegen ion is $\mathrm{Li}^{+}{ }^{7}$ On the other hand, Allen, et al., ${ }^{8}$ have shown that, in a similar toluene-THF mixture, anionic polymerization of MMA with $\mathrm{Na}^{+}$as a gegen ion is relatively simple as far as the kinetics is concerned.

A kinetic study of the anionic polymerization of MMA in pure THF has not yet been reported. But PMMA prepared anionically in THF at low temperature with $\mathrm{Na}^{+}$as a gegen ion is reported to have a very narrow molecular weight distribution and little isotactic structure. ${ }^{9-11}$ Hence, it is expected that the anionic polymerization of MMA under these conditions will be relatively simple and nearly the same in nature as the anionic polymerization of styrene in THF except for possible side reactions such as chain transfer or termination due to the presence of the carbomethoxy group. Methanol formation by carbonyl attack has often been reported for the nonpolar solvent $-\mathrm{Li}^{+}$systems. ${ }^{3,5,7}$ Consequently whether the same reaction is observed or not for THF $-\mathrm{Na}^{+}$system must be established before determination of propagation rate constants.

In this work dealing with the anionic polymerization of MMA in THF with $\mathrm{Na}^{+}$as a gegen ion, first, possible side reactions in the initiation and propagation steps are examined 


\section{Mita, Y. Watabe, T. Akatsu, and H. Kambe}

by analysis of methanol. Then from the kinetic data, the propagation rate constants of the polymerization are determined in comparison with those of styrene.

\section{EXPERIMENTAL}

\section{Materials}

MMA, purified by distillation over calcium hydride in nitrogen, was kept over calcium hydride in vacuo, then distilled in vacuo at least four times before use.

Sodium salt of $\alpha$-methylstyrene tetramer dianion and sodium naphthalene were used as initiators. The former was prepared according to Szwarc's method. ${ }^{12}$ The concentration of initiators was determined by alkali titration.

THF, used as a solvent, was purified as usual and kept as a green solutibn of sodium naphthalene. It was distilled from the solution just before use.

All the operations for the preparation of monomer solution, catalyst solution, etc., were carried out in high vacuum by using break-seal techniques.

Nitrogen, used as the source of pressure in the polymerization experiments, was purified by passing through reduced copper at $170^{\circ} \mathrm{C}$, followed by THF solution of sodium ketyl at room temperature.

\section{Polymerization}

The polymerization was followed by a capillary flow method. The apparatus is similar to that described by Szwarc, et al. ${ }^{13}$ To enhance mixing of the two solutions, a very tiny copper spiral was put in the hole of the three-way cock. Flow time of solution through the capillary was varied from 0.1 to $2 \mathrm{sec}$ by altering the nitrogen pressure over the solution. Break-sealed glass tubes, each containing monomer and initiator solution, were attached to an assembly of the flow apparatus. After this was evacuated thoroughly, the glass seals were broken to introduce the solutions into each main tube of the flow apparatus and nitrogen pressure was then applied. In the low temperature experiments, the main tubes were cooled by Dewer vessels containing Dry Ice-methanol. But in the first series of experiments, the three-way cock for mixing and the capillary were not cooled. As a result, the solution was not kept at $-78^{\circ} \mathrm{C}$ during polymerization though an initial ca. 10 $\mathrm{m} l$ of the cooled solution was used to cool down the capillary. By measuring the temperature of the solution at the exit of the capillary, the mean temperature of polymerization was estimated roughly to be about $-60^{\circ}$ to $-65^{\circ} \mathrm{C}$. In the second series of experiments, most of the apparatus was covered with mantles in which methanol at $-78^{\circ} \mathrm{C}$ was circulated and it was confirmed that the solution was kept near this temperature.

The living polymer was killed with methyl iodide in THF at the exit of the capillary. Flow time, which is equal to the reaction time, was calculated by dividing the sum of the volumes of mixing cock and capillary by the flow volume per second. Polymer yield was determined gravimetrically. The degree of polymerization of PMMA in this work is relatively low. Accordingly, to avoid the loss of oligomer due to incomplete precipitation, the reaction product was recovered as follows. After the polymerization, the solution was concentrated to about one third of its original volume and petroleum ether was added to precipitate the polymer. The solvent was removed again in vacuo and the polymer remaining was redissolved in benzene and freezedried at $0^{\circ} \mathrm{C}$. For the calculation of conversion, the weight of $\mathrm{NaI}$ and the catalyst was subtracted from the weight of the product.

To confirm the reliability of the method, styrene was polymerized with sodium naphthalene in THF at $20^{\circ} \mathrm{C}$. The apparent propagation rate constant obtained was $4.8 \times 10^{2} l \mathrm{~mol}^{-1} \mathrm{sec}^{-1}$ for a catalyst concentration of $4.7 \times 10^{-3} \mathrm{~mol} / l$. This is in close agreement with the reported value of $5.2 \times 10^{2} l \mathrm{~mol}^{-1} \mathrm{sec}^{-1}$ at $25^{\circ} \mathrm{C}$ for the same anion concentration. ${ }^{13}$

\section{Analysis of the Products}

Methanol and naphthalene in the killed polymer solution were determined by gas chromatograph (Yanagimoto GC-G-220 with flam ionization detector) using Apiezon L 5\% as stationary phase.

Molecular weight of PMMA was determined in benzene solution with a Mechrolab 302 vapor pressure osmometer. 


\section{RESULTS}

\section{Polymerization at Low Temperatures}

Polymerization was initiated with the dianion of $\alpha$-methylstyrene tetramer. Figures 1 and 2 show the first-order decrease in monomer concentration with reaction time at $-78^{\circ} \mathrm{C}$ and $\mathrm{ca}$. $-65^{\circ} \mathrm{C}$ respectively. The data at $c a .-65^{\circ} \mathrm{C}$ is a little scattered, perhaps because of temperature variation from one experiment to another due to different degrees of cooling of the capillary. In spite of this experimental fluctuation, it is clear that in both series of experiments, the rate is essentially first order with respect to monomer consumption. If there is no side reaction, the slope of the strainght line must give $k_{\mathrm{p}}\left[\mathrm{P}^{-}\right]_{0}$.

To know whether side reactions are present or not, the quantity of methanol, formed by the reaction of the carbomethoxy group with anion, was determined by gas chromatography. A rather large quantity of methanol was detected in the reaction mixture at $c a .-65^{\circ} \mathrm{C}$. The

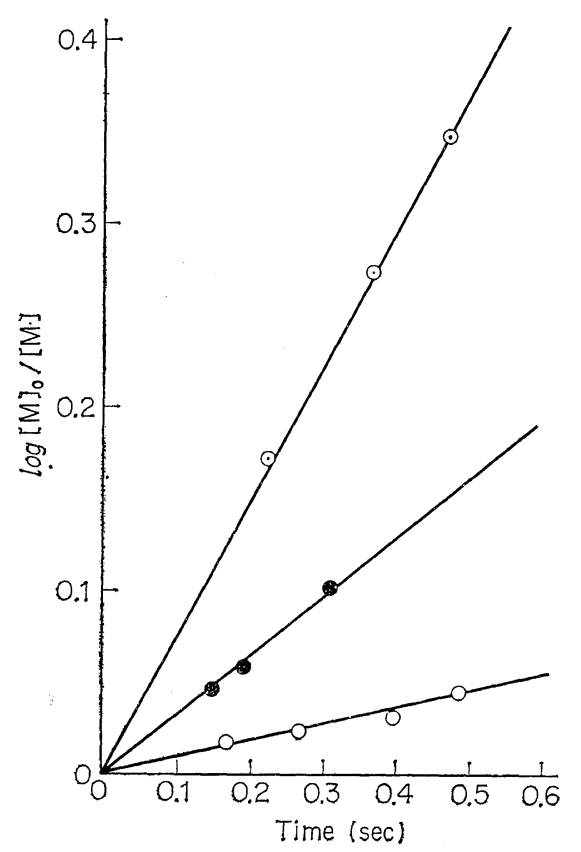

Figure 1. First-order plot of decrease in monomer concentration: initiator, dianion of $\alpha$-methylstyrene tetramer; temp, $-78^{\circ} \mathrm{C} ; \odot,[\mathrm{M}]_{0}=0.25 \mathrm{M},[\mathrm{I}]_{0}=$ $0.15 \mathrm{M} ; \bullet,[\mathrm{M}]_{0}=0.25 \mathrm{M},[\mathrm{I}]_{0}=0.0075 \mathrm{M} ; \bigcirc,[\mathrm{M}]_{0}=$ $0.25 \mathrm{M},[\mathrm{I}]_{0}=0.0015 \mathrm{M}$.

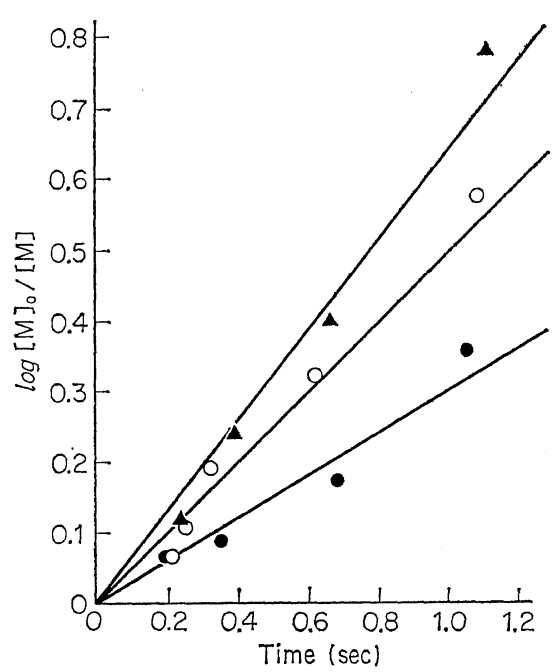

Figure 2. First-order plot of decrease in monomer concentration: initiator, dianion of $\alpha$-methylstyrene tetramer; temp, $c a . \quad-65^{\circ} \mathrm{C} ; \Delta,[\mathrm{M}]_{0}=0.237 \mathrm{M}$, $[\mathrm{I}]_{0}=0.0176 \mathrm{M} ; \bigcirc,[\mathrm{M}]_{0}=0.257 \mathrm{M},[\mathrm{I}]_{0}=0.012 \mathrm{M} ;$ $[\mathrm{M}]_{0}=0.247 \mathrm{M},[\mathrm{I}]_{0}=0.0067 \mathrm{M}$.

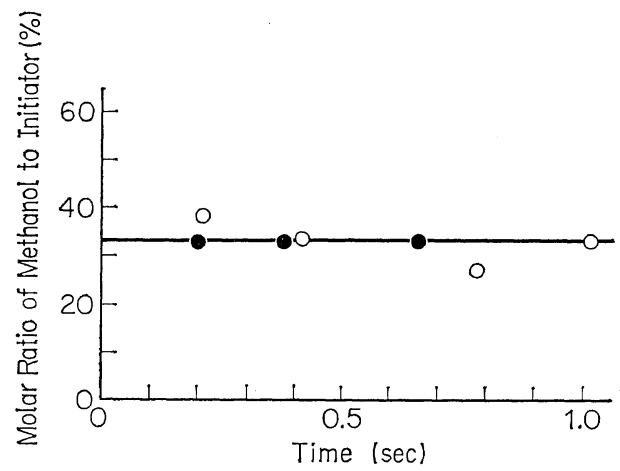

Figure 3. Amount of methanol formed during the polymerization: initiator, dianion of $\alpha$-methylstyrene tetramer; temp, $c a .-65^{\circ} \mathrm{C} ; \bigcirc,[\mathrm{M}]=0.23 \mathrm{M}$, $[\mathrm{I}]=0.017 \mathrm{M} ;[\mathrm{M}]=0.216 \mathrm{M},[\mathrm{I}]=0.0075 \mathrm{M} . \%$ is based on the initial anion concentration.

results of the analysis are given in Figure 3. It is seen that the molar ratio of formed methanol to initial initiator anion is not affected by the initial initiator concentration nor by the reaction time. No methanol was detected within experimental error at $-78^{\circ} \mathrm{C}$.

The increase in molecular weight of the polymer during the polymerization at $c a .-65^{\circ} \mathrm{C}$ is shown in Figure 4. The molecular weight increases linearly with conversion and extraporation 


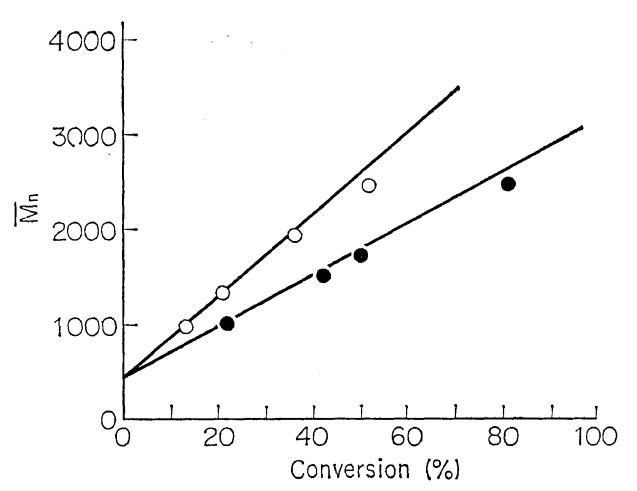

Figure 4. Molecular weight vs. conversion for the polymerization at $\mathrm{ca}$. $-65^{\circ} \mathrm{C}:-[\mathrm{M}]_{0}=0.237 \mathrm{M}$, $[\mathrm{I}]_{0}=0.0176 \mathrm{M}, \bigcirc,[\mathrm{M}]_{0}=0.257 \mathrm{M}, \quad[\mathrm{I}]_{0}=0.012 \mathrm{M}$. The straight lines are theoretical ones.

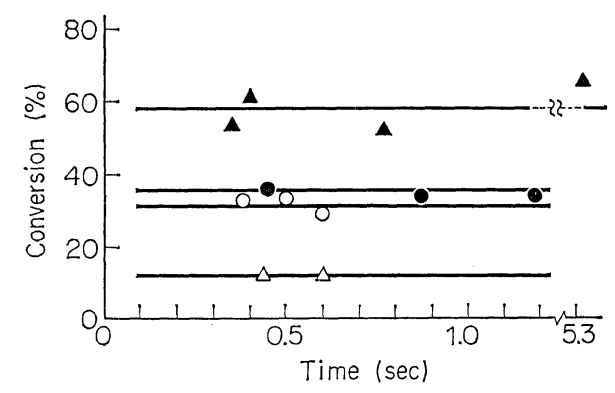

Figure 5. Polymerization of MMA at room temperature: initiator, sodium naphthalene; $\boldsymbol{\Delta}$, $[\mathrm{M}]_{0}=0.219 \mathrm{M},[\mathrm{I}]_{0}=0.012 \mathrm{M} ; \bigcirc,[\mathrm{M}]_{0}=0.222 \mathrm{M}$, $\left.\left.[\mathrm{I}]_{0}=0.006 \mathrm{M} ; \mathrm{C}^{\mathrm{M}}, \mathrm{M}\right]_{0}=0.109 \mathrm{M}, \mathrm{I}\right]=0.0035 \mathrm{M} ; \triangle$, $[\mathrm{M}]_{0}=0.100 \mathrm{M},[\mathrm{I}]_{0}=0.0011 \mathrm{M}$.

to zero conversion just corresponds to the molecuar weight of $\alpha$-methylstyrene tetramer.

\section{Polymerization at Room Temperature}

Sodium naphthalene was used as an initiator. At room temperature, polymerization was too fast to be followed by our method. Timeconversion curves given in Figure 5 shows that the reactions were already over in about 0.35 sec. The most important feature of the polymerization at room temperature is that the polymerization is terminated before $100-\%$ conversion. Another important point to be noted is that methanol is formed almost in stoichiometric relation to the amount of the initial catalyst. The results are given in Table I. The quantity of naphthalene recovered in the reaction
Table I. Methanl and naphthalene formed during the polymerization at room temperature initiated with sodium naphthalene.

\begin{tabular}{|c|c|c|c|c|c|c|}
\hline \multirow{2}{*}{$\begin{array}{l}{[\mathrm{M}]_{0},} \\
\mathrm{~mol} / l\end{array}$} & \multirow{2}{*}{$\begin{array}{c}{\left[\mathrm{I}_{0}\right],} \\
\mathrm{m} \mathrm{mol} / \mathrm{l}\end{array}$} & \multirow{2}{*}{$\begin{array}{c}\text { Reaction } \\
\text { time, sec }\end{array}$} & \multicolumn{2}{|c|}{ Methanol } & \multicolumn{2}{|c|}{ Naphthalene } \\
\hline & & & $\mathrm{m} \mathrm{mol} / l$ & $\%^{a}$ & $\mathrm{mmol} / l$ & $\%$ \\
\hline 0.221 & 13 & 1.15 & 10 & 80 & 5.0 & 39 \\
\hline 0.221 & 13 & 0.24 & 12 & 91 & 5.6 & 43 \\
\hline 0.221 & 7.0 & 1.70 & 7.1 & 104 & 3.0 & 44 \\
\hline 0.221 & 7.0 & 0.24 & 6.9 & 101 & 3.1 & 46 \\
\hline 0.221 & 3.3 & 0.94 & 3.1 & 97 & 1.6 & 48 \\
\hline 0.221 & 3.3 & 0.30 & 2.8 & 92 & 1.6 & 48 \\
\hline
\end{tabular}

a $\%$ based on $[\mathrm{I}]_{0}$.

mixture is also given in the table.

\section{DISCUSSION}

One of the important problems in the anionic polymerization of polar monomers such as MMA and $\mathrm{AN}$ is the reaction of the functional group in the monomer and polymer with carbanions, both in the initiation and propagation steps. As already mentioned, methanol, produced by the reaction of carbomethoxy groups with anions, has been detected often during anionic polymerization of MMA in nonpolar solvents..$^{3,5,7}$

Figure 3 shows that methanol is in fact formed also in the polymerization of MMA in THF at ca. $-65^{\circ} \mathrm{C}$, but the quantity of methanol produced is constant throughout the polymerization. Consequently, it is concluded that methanol is formed only during the initiation step and not during propagation. The different behavior of the carbomethoxy group toward the initiating and propagating carbanions is explained by the much weaker basicity of the propagating PMMA anion as compared with that of the oligo $(\alpha-$ methylstyryl) anion used as an initiator. Our result is consistent with the known fact that when the living polystyryl dianion or monoanion is mixed with PMMA in solution, the anion loses its reactivity and gel or graft polymer is formed ${ }^{14,15}$ while the anion of PMMA does not react with dead PMMA in the same way. ${ }^{15}$

The molar ratio of formed methanol to initiator is independent of the initial initiator concentration. The efficiency of the initiation reaction at $c a .-65^{\circ} \mathrm{C}$ is about $66 \%$. At the 
initiation step, there is no polymer. Hence, the ratio of $66: 34$ or about $2: 1$ can be considered as the ratio of the reactivity of the vinyl double bond to that of the carbonyl double bond in MMA monomer toward the oligo $(\alpha$-methylstyryl) anion at this temperature. This ratio is very similar to that obtained by Tsuruta, et al. ${ }^{16}$ $(38: 17)$ for the initiation reaction of MMA with $n$-BuLi in THF at $-70^{\circ} \mathrm{C}$ though their anion and gegen cation are different from ours. In the case of BuLi, hydrogen abstraction is the most important reaction (45\%). As will be shown later, however, the growing PMMA anion does not cause any chain transfer from the monomer. The resonance stabilized $\operatorname{oligo}(\alpha-$ methylstyryl) anion may also be much less reactive than the butyl anion. Hence, we ignored here the possibility of the hydrogen abstraction.

At $-78^{\circ} \mathrm{C}$, no methanol was detected. This is surprising in spite of the relatively small temperature difference in the two series of experiments. However, it is possible that the difference in activation energy between the reactions of the initiating anion with vinyl and carbonyl double bonds is rather large.

During the propagation step, methanol is formed neither at $-78^{\circ} \mathrm{C}$ nor at $\mathrm{ca} .-65^{\circ} \mathrm{C}$. If there is any other termination reaction which does not give methanol, the concentration of propagating anion must decrease and $-\log [\mathrm{M}]$ will not be linear with time. This is not the case. If any transfer reaction which regenerates the active anion occurs, $-\log [\mathrm{M}]$ vs. time remains linear but the molecular weight of the polymer must be smaller than the expected value. Figure 4 shows that the number-average molecular weights of the polymers recovered for the polymerization at $c a .-65^{\circ} \mathrm{C}$ are not only proportional to conversion but they agree well with those calculated by assuming no chain transfer (straight lines). It is noted that the initiation efficiency does not affect the number average molecular weight in our experiments because the polymer recovered contains all the initiator fragments. Further as will be reported elsewhere, ${ }^{17}$ we have obtained PMMA with molecular weight of several millions in the anionic polymerization of MMA in THF at $-78^{\circ} \mathrm{C}$ with sodium salt of aldehyde ion-radical as a catalyst. This means that the chain transfer reaction is almost absent in the anionic polymerization of MMA in THF at low temperature with $\mathrm{Na}^{+}$as a gegen ion.

In the experiments at room temperature, sodium naphthalene was used as an initiator. The catalyst is known to initiate the polymerization of MMA by electron transfer from the catalyst to the monomer leaving naphthalene as a by-product. ${ }^{18}$ On the other hand, we have reported that sodium naphthalene initiates the polymerization of aldehyde through addition of the catalyst to the carbonyl group of aldehyde. ${ }^{19}$ Accordingly, it is natural to assume that the quantity of naphthalene recovered in the polymerization of MMA corresponds to the amount consumed in the normal initiation reaction and the remainder to the carbonyl addition. Table I shows that about half of the initiator is used for the initiation with no respective of the initiator concentration.

Methanol is formed stoichiometrically with respect to the initial initiator concentration at room temperature. This means that besides the methanol formation by carbonyl attack at the initiation step, all the growing carbanion is also transformed finally to methoxide ion by the reaction with carbomethoxy groups, i.e., a kind of termination reaction. In fact, the polymerization stops at a certain conversion at room temperature (Figure 5). It is possible to estimate the mean degree of polymerization of the polymer from the final conversion, initial $[\mathrm{M}]_{0} /[\mathrm{C}]_{0}$ and initiation efficiency. As is shown in Table II, this is about 24 per anion with no respective of the conversion and the initial monomer concentration. This result suggests that the growing

Table II. Calculated average degree of polymerization per propagating anion in the polymerization at room temperature.

\begin{tabular}{lcccc}
\hline $\begin{array}{l}{[\mathrm{M}]_{0},} \\
\mathrm{~mol} / l\end{array}$ & $\begin{array}{c}{[\mathrm{I}]_{0},} \\
\mathrm{~m} \mathrm{~mol} / l\end{array}$ & {$[\mathrm{M}]_{0} /[\mathrm{I}]_{0}$} & $\begin{array}{c}\text { Con- } \\
\text { version, } \\
\%\end{array}$ & $\overline{\mathrm{DP}}_{n} /$ end $^{\mathrm{a}}$ \\
\hline 0.219 & 12 & 18.4 & 58 & 24 \\
0.222 & 6 & 32.0 & 31 & 22 \\
0.109 & 3.5 & 31.0 & 35 & 24 \\
0.100 & 1.1 & 90.9 & 12 & 24 \\
\hline
\end{tabular}

a Initiation efficiency was taken as $45 \%$. 
PMMA anion reacts with the carbomethoxy group of the monomer but not with that of the polymer. If the rate of the termination reaction is expressed by $k_{\mathrm{t}}[\mathrm{P}][\mathrm{M}]$, then the degree of polymerization per anion, being the ratio of the rates of propagation to termination, is given by $k_{\mathrm{p}} / k_{\mathrm{t}}$ which is independent of the total carbomethoxy group concentration. A similar situation was found for the anionic polymerization of MMA in THF at $-78^{\circ} \mathrm{C}$ with sodium benzaldehyde ion-radical as an initiator ${ }^{17}$ though the ratio of $k_{\mathrm{p}} / k_{\mathrm{t}}$ is very much higher than the value at room temperature given above.

The apparent second order propagation rate constants for the polymerization at $-78^{\circ} \mathrm{C}$ and ca. $-65^{\circ} \mathrm{C}$ are calculated from the slopes in Figures 1 and 2, the initiation efficiency being taken into consideration. They are in the range of 1 to $2 \times 10^{2} l \mathrm{~mol}^{-1} \mathrm{sec}^{-1}$ as shown in Table III. At room temperature, the polymerization

Table III. Apparent propagation rate constant $\left(k_{\mathrm{p}}\right)$ for the polymerization of MMA at low temperatures

\begin{tabular}{ccccc}
\hline $\begin{array}{c}\text { Tempera- } \\
\text { ture, }{ }^{\circ} \mathrm{C}\end{array}$ & $\begin{array}{c}{[\mathrm{M}]_{0},} \\
\mathrm{~mol} / l\end{array}$ & $\begin{array}{c}{[\mathrm{I}]_{0},} \\
\mathrm{mmol} / l / l\end{array}$ & $\begin{array}{c}\text { Concentration } \\
\text { of propagating } \\
\text { anion, m mol } / l\end{array}$ & $\begin{array}{c}k_{\mathrm{p}} \times \mathrm{b} \\
10^{-2}, \\
\mathrm{~mol}^{-1} \\
\mathrm{sec}^{-1}\end{array}$ \\
\hline$-60 \sim-65$ & 0.237 & 17.6 & $11.7^{\mathrm{a}}$ & 1.3 \\
$-60 \sim-65$ & 0.257 & 12 & $8.0^{\mathrm{a}}$ & 1.4 \\
$-60 \sim-65$ & 0.247 & 6.7 & $4.5^{\mathrm{a}}$ & 1.5 \\
-78 & 0.250 & 15.0 & 15.0 & 1.1 \\
-78 & 0.250 & 7.5 & 7.5 & 1.0 \\
-78 & 0.250 & 1.5 & 1.5 & 1.4 \\
\hline
\end{tabular}

a Initiation efficiency was taken as $66 \%$.

b The error may be of the order of \pm 0.1 .

is too fast to be followed. It is already completed within $0.35 \mathrm{sec}$. Consequently, the rates of polymerization must be faster than the rates calculated by assuming that the conversions take $0.35 \mathrm{sec}$. Then the lowest limit of the propagation rate constant at room temperature can be estimated as about $10^{3} l \mathrm{~mol}^{-1} \mathrm{sec}^{-1}$.

To estimate the contribution of the ion pair (rate constant, $k_{ \pm}$) and that of free ion $\left(k_{-}\right)$to the apparent propagation rate constant, the latter was plotted against $\left[\mathrm{P}^{-}\right]_{0}^{-1 / 2}$ in Figure 6 where $\left[\mathrm{P}^{-}\right]_{0}$ is the total concentration of the propagat-

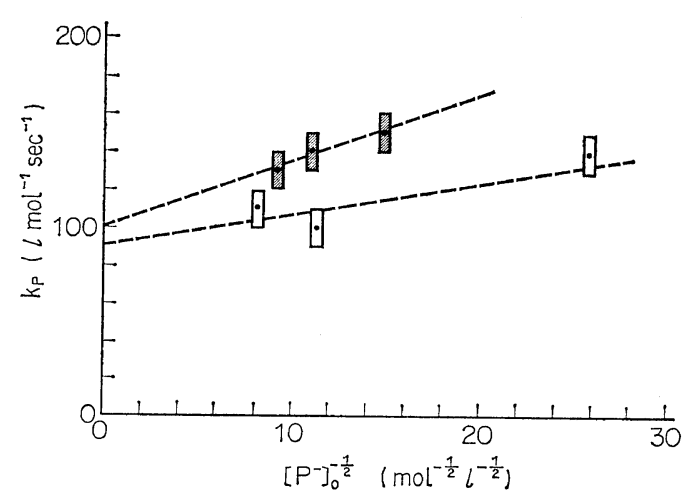

Figure 6. Dependence of apparent propagation rate constants $\left(k_{\mathrm{p}}\right)$ on the concentration of propagating anion: initiator, dianion of $\alpha$-methylstyrene; $\square,-78^{\circ} \mathrm{C}$; 缓, $c a .-65^{\circ} \mathrm{C}$.

ing anion. Though the data are not numerous, it is clear that $k_{ \pm}$at these low temperatures is about $1 \times 10^{2} l \mathrm{~mol}^{-1} \mathrm{sec}^{-1}$ and the contribution of the free ion to the total propagation is relatively small in the initiator concentration range studied. Figueruelo ${ }^{20}$ has reported the dissociation constant of living $\mathrm{PMMA}^{-} \mathrm{Na}^{+}$in THF at $-78^{\circ} \mathrm{C}$ as about 2 to $4 \times 10^{-10} \mathrm{~mol} / \mathrm{l}$ which is far less than that of polystyryl sodium in THF at the same temperature. The very small concentration of free PMMA anion may explain its small contribution to the propagation reaction.

The ion-pair propagation rate constant of $\mathrm{PMMA}^{-} \mathrm{Na}^{+}$thus obtained is lower than that of polystyryl sodium at the same temperature $(250$ and $280 \mathrm{lmol}^{-1} \mathrm{sec}^{-1}$ at -60 and $-80^{\circ} \mathrm{C}$ respectively ${ }^{21}$ ). However, before a direct comparison of these values is made, we will discuss the nature of the ion pair of PMMA $\mathrm{Na}^{+}$. The inter-ionic distance of the solvent-separated polystyryl sodium in THF, estimated from its dissociation constant $\left(2 \times 10^{-6} \mathrm{~mol} / l^{23}\right)$ by using the Fuoss' semiquantitative equation ${ }^{22}$, is about $5 \AA$ whereas less than $3 \AA$ are obtained for $\mathrm{PMMA}^{-} \mathrm{Na}^{+}$. Though the equation does not take into account of the effect of solvation of the free cation in the case of the contact ion-pair, the above fact suggests strongly that the $\mathrm{PMMA}^{-} \mathrm{Na}^{+}$ion-pairs in THF may consist mainly of contact ion-pairs. This seems to be also supported by the fact that the apparent rate constant is much higher at room temperature than at low temperatures, 
a fact which is in contrast to the case of the polymerization of styrene.

Based on the generally known behavior that the effect of a substituent is much stronger for monomer than for the anion in the anionic polymerization, ${ }^{22}$ we suppose that the strong electronattracting carbomethoxy group in MMA will increase very much the reactivity of the monomer towards the propagating ions as compared with that of styrene, while the same substituent will decrease the reactivity of the propagating PMMA anion towards monomers far less strongly; the consequence is that MMA is homopolymerized anionically faster than styrene. However, the argument may hold only for the comparison of the same species i.e., contact ion-pair to contact ion-pair and solvent-separated ion pair to solventseparated ion pair. The apparent high rate of the ion-pair polymerization of styrene as compared with that of MMA may results from the fact that the ion-pair polymerization of styrne in THF at low temperature proceeds mainly by the solvent-separated ion pair ${ }^{21}$ whereas that of MMA proceeds mainly by contact ion-pair.

Next, the copolymerization of MMA and styrene will be discussed where the over-all apparent propagation rate constants are important. The low rate of polymerization of MMA relative to styrene must be more pronounced for the over-all apparent propagation than for the ionpair propagation because the contribution of free ion to the apparent rate of homopolymerization of styrene is relatively large in THF at low temperature. It is interesting that MMA $\left(\mathrm{M}_{1}\right)$, which is polymerized almost exclusively in the anionic homogeneous copolymerization with styrene $\left(\mathrm{M}_{2}\right)$, has a lower rate of homopolymerization than styrene at these low temperatures. A similar situation is known for the anionic copolymerization of butadiene with styrene in nonpolar solvent with $\mathrm{Li}^{+}$as a gegen ion. ${ }^{23}$ O'Driscoll, et al. ${ }^{24}$ have explained this satisfactorily by attributing a very large value and a very small value to each of the two crosspropagation constants. In the same way, the copolymerization of MMA and styrene is explained by the following relation which includes the present result $k_{21} \gg k_{22}>k_{11} \gg k_{12}$, i.e., the growing polystyryl anion is converted immediate- ly to PMMA anion while the latter reacts hardly with styrene. In fact, the inability of PMMA anion to add to styrene is known $^{25}\left(k_{12}=0\right)$. The rate of initiation of MMA by oligostyryl or olygo( $\alpha$-methylstyryl) anions may be much faster than the rate of propagation of MMA $\left(k_{21} \ll k_{11}\right)$.

The above relation shows that the composition equation, derived also by $\mathrm{O}^{\prime} D$ riscoll ${ }^{26}$ for the anionic copolymerization of styrene and MMA or for any combination of monomers with relatively large difference in electonegativity, does not hold at least in our case because the equation is based on the assumption that both $k_{12}$ and $k_{21}$ are very small.

Our results show that not only for the butadiene-styrene system in nonpolar solvent where the reaction is complicated because of the association of the propagating anions and the coordination of monomers to $\mathrm{Li}^{+}$, but even for a normal anionic copolymerization such as that of styrene with MMA in THF, the nearly exclusive polymerization of $M_{1}$ does not warrant necessarily a higher rate of homopolymerization of $M_{1}$ than $M_{2}$ and that the crosspropagation rate constants must be considered judiciously.

Acknowledgement. The authors wish to express their heartful appreciation to Mr. I. Imai for his helpful assistance in carrying out the experiments.

\section{REFERENCES}

1. D. L. Glusker, E. Stiles, and B. Yoncoskie, $J$. Polym. Sci., 49, 297 (1961).

2. D. L. Glusker, I. Lysleff, and E. Stiles, $J$. Polym. Sci., 49, 315 (1961).

3. D. M. Wiles and S. Bywater, Polymer, 3, 175 (1962).

4. B. J. Cottam, D. M. Wiles, and S. Bywater, Can. J. Chem., 41, 1905 (1963).

5. D. M. Wiles and S. Bywater, J. Phys. Chem., 68, 1938 (1964).

6. D. M. Wiles and S. Bywater, Trans. Faraday Soc., 61, 150 (1964).

7. D. L. Glusker, R. A. Gallucio, and R. A. Evans, J. Amer. Chem. Soc., 86, 187 (1964).

8. P. E. M. Allen, D. O. Jordan, and M. A. Naim, Trans. Faraday Soc., 63, 234 (1967).

9. A. Roig, J. Figueruelo, and E. Llano, J. Polym. Sci., Part B, 3, 171 (1965).

10. H. Ohnuma, T. Kotaka, and H. Inagaki, 
Polymer J., 1, 716 (1970).

11. T. Miyamoto and H. Inagaki, ibid., 1, 46 (1970).

12. C. L. Lee, J. Smid, and M. Szwarc, J. Phys. Chem., 66, 904 (1962).

13. C. Geacintov, J. Smid, and M. Szwarc, J. Amer. Chem. Soc., 84, 2508 (1962).

14. H. Schreiber, Makromol. Chem., 36, 86 (1959).

15. P. Rempp, V. I. Volkov, J. Parod, and C. Sadron, Vyskomol. Soedin., 2, 1521 (1960).

16. N. Kawabata and T. Tsuruta, Makromol. Chem., 86, 231 (1965).

17. I. Mita, S. Yabe, and H. Kambe, Presented at the International Symposium on Macromolecular Chemistry, Tokyo-Kyoto, 1966, to be published.

18. A. V. Tobolsky and D. B. Hartley, J. Amer. Chem. Soc., 84, 1391 (1962).
19. I. Mita, S. Yabe, I. Imai, and H. Kambe, Makromol. Chem., 137, 133 (1970).

20. J. E. Figueruelo, Makromol. Chem., 131, 63 (1970).

21. T. Shimomura, K. J. Tolle, J. Smid, and M. Szwarc, J. Amer. Chem. Soc., 89, 796 (1967).

22. M. Swarc, "Carbanions, Living Polymers and Electron Transfer Process," Interscience, New York, N. Y., 1968.

23. A. A. Korotkov and G. V. Rakoua, Vysokomol. Soedin., 3, 1482 (1961).

24. K. F. O'Driscoll and I. Kuntz, J. Polym. Sci., 61, 19 (1962).

25. R. K. Graham, D. L. Dunkelberger, and W. E. Goode, J. Amer. Chem. Soc., 82, 400 (1960).

26. K. F. O'Driscoll, J. Polym. Sci., 57, 721 (1962). 